\section{Processos mentais em experienciação de desejos e construção de identidades em moradores de um distrito de Pernambuco}

Valmir Joaquim da SILVA JUNIOR (UFPE) valmir_joa@hotmail.com

Maria Medianeira de SOUZA (UFPE) medianeirasouza@yahoo.com.br

Recebido em: 30 de out. de 2019. Aceito em: 05 de maio de 2020.
SILVA JUNIOR, Valmir Joaquim da; SOUZA, Maria Medianeira de. Processos mentais em experienciação de desejos e construção de identidades em moradores de um distrito de Pernambuco. Entrepalavras, Fortaleza, v. 10, n. esp., p. 84-100, ago. 2020. DOI: $10.22168 / 2237-6321-$ gesp1761.

Resumo: O presente trabalho tem por objetivo investigar como se dá a experienciação do desejo em moradores do distrito de Tejucupapo, localizado no município de Goiana, no Estado de Pernambuco. O intuito foi perceber quais e como os desejos são construídos no discurso dessas pessoas, por meio do Processo Mental querer, e como aspectos identitários são revelados. Esta pesquisa é parte de uma dissertação de mestrado defendida na Universidade Federal de Pernambuco, em 2017. Para realizar este recorte, tomamos por base os pressupostos de Halliday e Matthiessen (2014) e Figueiredo (2011) sobre os Processos Mentais, especialmente os chamados Desiderativos, responsáveis por materializar os desejos, bem como Bucholtz e Hall (2005), entre outros, para discutir a noção de identidade. Após transcrição das entrevistas, foi realizado um mapeamento das ocorrências do Processo querer. A análise dos usos desse Processo mostrou que os desejos experienciados apontam para uma forte religiosidade, tendo em vista o expressivo número de ocorrências nas quais Deus e Jesus foram os Experienciadores. Também fomos capazes de ver como os participantes da pesquisa marcam suas 
identidades por meio da diferença, quando apontam que outros tejucupapenses têm anseios diferentes dos seus. Por fim, a análise revelou o otimismo e a esperança como traços particulares desses indivíduos.

Palavras-chave: Desejos. Identidade. Tejucupapo.

Abstract: This paper aims to investigate how desire is experienced in residents of the Tejucupapo district, located in Goiana, Pernambuco State. The aim was to understand what and how desires are constructed in the speech of these people, through the Mental Process want, and how identity aspects are revealed. This research is part of a master's dissertation defended at Federal University of Pernambuco, in 2017. To make this cut, we take as basis the assumptions of Halliday e Matthiessen (2014) and Figueiredo (2011) about the Mental Processes, especially the so-called Desideratives, responsible for materializing the desires, as well as Bucholtz and Hall (2005), among others, to discuss the notion of identity. After transcribing the interviews, a mapping of occurrences of the Process want was performed. The analysis of the uses of this Process showed that the experienced desires point to a strong religiosity, considering the expressive number of occurrences to which God and Jesus were Sensers. We were also able to see how the research participants mark their identities through difference when they point out that other Tejucupapenses have different yearnings than their own. Finally, the analysis revealed optimism and hope as particular traits of these individuals.

Keywords: Wishes. Identity. Tejucupapo.

\section{Introdução}

Acreditamos que é também pela linguagem que os indivíduos constituem e deixam transparecer suas identidades. As idiossincrasias de um grupo de indivíduos e a relação que eles estabelecem com as pessoas e o lugar que os circundam estão salientes em seus discursos, que, por sua vez, são materializados nos textos (FAIRCLOUGH, 2001). Consideramos, pois, que é por meio da linguagem que os sujeitos tomam posições no mundo, expressando sentimentos, desejos, crenças; representando e interpretando, de forma subjetiva, o mundo que está a sua volta; e assim, construindo sua identidade e, por vezes, reconstruindo-a de acordo com a situação interacional (MARCUSCHI, 2008).

Como já mencionado, este trabalho retoma parte da discussão empreendida em uma dissertação de mestrado, na qual foi analisado como os Processos Mentais evidenciavam elementos da identidade de um grupo de moradores de Tejucupapo. Baseados nisso, neste recorte pretendemos demonstrar como o Processo Mental querer desnuda características e subjetividades dos falantes. Dessa forma, entendemos que os desejos fazem parte de um espectro de sentimentos que constituem esses indivíduos. Ao torná-los conhecidos, as pessoas deixam revelar 
v. 10 (esp)

84-100 ago. 2020 aspectos de sua identidade, não apenas quando mencionam desejos que têm para si, mas também quando reportam desejos alheios, que são percebidos por meio de uma visão subjetiva de mundo.

É com essa visão, de relação intrínseca entre linguagem, sociedade e indivíduo, que este trabalho tem por objetivo analisar como os moradores de Tejucupapo, distrito que pertence ao município de Goiana, localizado no estado de Pernambuco, deixam transparecer suas identidades através dos seus desejos. Para realizar tal empreendimento, será utilizado o Processo Mental Desiderativo, um subtipo de Processo Mental, categoria que advêm do arcabouço teórico que integra a Linguística Sistêmico-Funcional, doravante LSF. Os Processos Mentais são classificados em quatro diferentes tipos, a saber: Perceptivos, Cognitivos, Emotivos e Desiderativos, conforme Halliday e Matthiessen (2014).

A LSF é uma teoria que busca compreender como estruturas da linguagem contribuem para o significado de um texto, isto é, como os significados são construídos no texto. Assim a LSF pode ser um caminho para o estudo de diversas questões relacionadas à tríade linguagem, indivíduo e sociedade, entre elas a identidade. O arcabouço teórico da referida teoria é o ponto de partida para outras correntes, a exemplo da Análise Crítica do Discurso. Esta perspectiva teórica, também preocupada com os significados no texto e com a tríade citada acima, volta-se para a intervenção social como forma de produzir mudanças que beneficiem aqueles que se encontrem em situação desfavorável. Acreditamos que tanto a LSF, quanto correntes que de alguma forma utilizam seus pressupostos, como a Análise Crítica do Discurso, podem ser pertinentes quando se pretende estudar linguagem, identidade e sociedade, pois fornecem instrumentos teóricos e metodológicos para tal. Neste trabalho, utilizaremos as concepções da LSF, especificamente no que concerne aos Processos Mentais Desiderativos, por acreditarmos que elas atendam e se encaixem aos propósitos e objetivos da pesquisa.

\section{A Linguística Sistêmico-Funcional: explorando significados}

A teoria de cunho funcionalista de Halliday, a Linguística Sistêmico-Funcional, começa a desenvolver-se no final dos anos 50 e começo dos anos 60 na Grã-Bretanha, de acordo com Ghio e Fernandez (2008). A perspectiva hallidayana pressupõe uma concepção de língua como um recurso para construir e interpretar significados em contextos 
sociais. As opções que os falantes da língua realizam são materializadas linguisticamente e discursivamente por meio de um processo de escolha. A LSF sustenta que a linguagem é usada por meio de escolhas, conscientes ou não, que são possíveis no nosso sistema linguístico. $\mathrm{O}$ falante seleciona os recursos léxico-gramaticais e utiliza-os na ocasião em que considera mais adequada aos seus propósitos comunicativos.

Tais linguistas propõem três funções básicas referentes à linguagem e que estão ligadas às variáveis Campo, Relações e Modo: compreender e representar a realidade; relacionar-se com o outro; e organizar as duas primeiras sob forma de texto. Os autores associaram tais funções a três metafunções: ideacional, interpessoal e textual, respectivamente. Metafunção é um termo usado para se referir a essas funções abstratas que são propriedades inerentes a todas as línguas. A metafunção que será explorada mais atentamente neste trabalho é a ideacional. Tal metafunção se dá "quando o indivíduo expressa a sua experiência do mundo material ou de seu mundo interior (o de sua própria consciência)" (FUZER; CABRAL, 2010, p. 26). A metafunção interpessoal entende a oração como troca, a atenção se volta para a interação entre os participantes de um evento comunicativo. Já a metafunção textual é a responsável pela organização dos significados ideacionais e interpessoais em um todo coerente: o texto.

As manifestações dos significados experienciais e representacionais se dão no Sistema de Transitividade. A LSF entende a Transitividade como categoria gramatical relacionada à Metafunção Ideacional, que materializa a representação das ideias, da experiência humana. Para Furtado da Cunha e Souza (2011), o Sistema de Transitividade possibilita a identificação das ações e atividades humanas que estão sendo expressas no discurso e da realidade que está sendo retratada. A transitividade é, dessa forma, um sistema de descrição de toda a oração, que se compõe de Processos, Participantes e eventuais Circunstâncias.

Na LSF, há seis processos pelos quais acontece a representação da experiência humana: Materiais, Mentais, Relacionais, Verbais, Existenciais e Comportamentais. O foco deste trabalho são os Processos Mentais, especialmente os ditos Desiderativos, os quais representam a experiência interna, e seus Participantes. ${ }^{1}$

${ }^{1}$ Para mais detalhes a respeito dos outros tipos de Processos, cf. Halliday e Matthiessen (2014). 
v. 10 (esp)

84-100

ago.

2020

Os processos mentais

Os Processos Mentais são os responsáveis por externalizar o mundo experiencial de nossa própria consciência, ou seja, o lado interno da experiência. São eles que têm por função representar o universo vivenciado em nosso interior, que existe dentro de nós, mas que, por sua vez, foi construído e/ou influenciado pelas experiências no mundo externo, ou seja, pela face sociocultural da experiência. Os participantes constituintes das orações com Processos Mentais são Experienciador e Fenômeno, além do próprio Processo, realizado por grupos verbais.

Halliday \& Matthiessen (2014) vão classificá-los e dividi-los em quatro tipos: os Processos Mentais Perceptivos (ver, escutar, perceber, sentir); os Processos Mentais Cognitivos (achar, compreender, conhecer, saber); os Processos Mentais Emotivos (adorar, agradar, amar, detestar); e os Processos Mentais Desiderativos (cobiçar, desejar, pretender, querer). Esse último, foco deste trabalho, será o tema da seção a seguir.

Os desiderativos

Esses processos são responsáveis por externalizar vontades, desejos e interesse em relação a algo. Figueiredo (2011) aponta que tais processos atuam quase exclusivamente como atual ${ }^{2}$, categoria temporal que se refere ao desdobramento do Processo com base no momento de enunciação e que tem como tempo verbal prototípico o presente simples. Normalmente têm a propriedade de criar o Fenômeno que, na maioria das vezes, se apresenta de forma abstrata, por meio de orações hipotáticas subjuntivas, como no exemplo a seguir:

(01) Ele não quer que você tire a vida de ninguém... ${ }^{3}$

De acordo com Figueiredo (2011), o conteúdo dos Processos Desiderativos são ideias baseadas em desejo e sempre hipotéticas. Por isso, podem ser realizados por orações não finitas quando o Experienciador e o participante da oração projetada são o mesmo, ou por uma oração 'que' quando estes são diferentes. Dessa forma, os Processos Desiderativos são divididos em dois subtipos. O primeiro subtipo, Tipo 'querer', indica uma ideia que é realizada na gramática

\footnotetext{
${ }^{2}$ Significa uma duração ilimitada do desdobramento temporal, sem demarcação de início ou fim do Processo.
}

3 Todos os exemplos foram extraídos do nosso corpus. 
pela oração não finita tendo como Participante o mesmo elemento que é realizado pelo Experienciador, caso do exemplo (02); o segundo, indica uma ideia que se espera acontecer, o Tipo 'esperar' - realizada por uma oração 'que' e o grupo verbal com morfologia subjuntiva, como mostra o excerto (03).

(02) A gente quer fazer as coisas e não pode...

(03) Quero que Jesus me abençoe até o final da minha vida...

Os Processos Desiderativos podem também envolver um outro Participante, além do Fenômeno, o qual possui a função de Beneficiário, que seria o recebedor do desejo ou dos votos, o que não é possível perceber com os outros subtipos de Processo Mental.

(04) Eu só quero que ele seje fiel comigo como eu sou com ele...4

Alguns exemplos de Processos Mentais Desiderativos do Português são: almejar, ansiar, aquiescer, aspirar, cobiçar, concordar, decidir, desejar, determinar, esperar, estabelecer, obedecer, opor, planejar, pretender, projetar, querer, recusar, refugar, rejeitar, repelir, resolver, sujeitar-se, tencionar, tentar, sonhar. ${ }^{5}$

Um pouco sobre Tejucupapo

Tejucupapo é um distrito do município de Goiana, a $60 \mathrm{~km}$ da capital do Estado de Pernambuco, contando com uma população de, aproximadamente, dez mil habitantes. Em 2017, o lugar passou a integrar a região metropolitana de Recife. Essa região tem uma importância histórica por se tratar de uma das primeiras áreas onde se deu o processo de colonização do Brasil.

Há mais de três séculos, os moradores dessa região lutaram contra uma invasão holandesa. Nessa ocasião as mulheres tiveram um papel importante no embate, razão pela qual a batalha de Tejucupapo é conhecida como primeira luta com a participação ativa das mulheres no Brasil. Os holandeses, já sem recursos, decidem invadir áreas do litoral do estado de Pernambuco em busca de alimentos; uma delas foi

${ }^{4}$ Os exemplos foram transcritos respeitando a fala dos entrevistados.

${ }^{5}$ Lista baseada em Fuzer e Cabral (2010). 
v. 10 (esp)

84-100 ago. 2020
Tejucupapo. Após duas investidas de sucesso desses invasores, que a essa altura já não tinham mais munição, as mulheres de Tejucupapo se organizaram e, com ajuda de uma solução com água quente e pimenta, além de pedaços de madeira, conseguiram expulsar os holandeses e salvar seus mantimentos. Esse fato histórico, entretanto, parece não ter tido espaço nos nossos livros de história, embora seja lembrado anualmente com a realização de uma peça de teatro na região, o que mostra a importância desse acontecimento para Tejucupapo e seu povo.

Hoje, Tejucupapo se configura como uma comunidade muito pobre, cujas principais fontes de renda são oriundas do trabalho de pesca, do corte de cana-de-açúcar, da plantação em roças e dos benefícios de programas sociais como bolsa família, bolsa verde, aposentadorias etc. Vê-se, atualmente, que os tejucupapenses tanto conservam hábitos ligados a uma vida mais rural, característicos do próprio distrito de Tejucupapo, quanto são afetados por um padrão de vida mais urbano, oriundos tanto de Goiana, como de municípios mais próximos como Igarassu e Abreu e Lima. Dessa forma, vamos perceber nas análises como essa configuração e esse casamento entre rural e urbano apresentam-se em seus discursos.

\section{Como construímos Identidades}

Os estudos mais recentes de identidade propõem que esta deve ser elaborada e construída discursivamente. Essa forma de lidar com a identidade não equivale à noção desse fenômeno enquanto essência individual, perspectiva que foi pioneira nos estudos sobre o tema. Magalhães (2013) aponta que a construção da identidade é um ato performativo, cuja realização se dá quando as pessoas se colocam e interagem nas mais diversas situações. É relevante mencionar que nessa perspectiva a constituição da identidade é um "processo negociado de exposição e de posições de interpretações sociais, afiliações, papéis, status e outras categorias sociais" (MAGALHÃES, 2013, p. 32).

Um autor cujos estudos vão corroborar com essa noção de identidade é Moita Lopes (2002), ao se debruçar sobre o estudo das identidades múltiplas que se encontram no discurso. Tal autor vai defender que a identidade emerge das práticas discursivas, configurandose, dessa forma, como um construto de natureza social.

Para Silva, Hall e Woodward (2000), a identidade é também marcada pela diferença. Tal diferença pode ser estabelecida por uma 
marcação simbólica. E, para os autores, essa diferença é sustentada pela exclusão: se você é uma coisa, você não pode ser outra. Mas essa afirmação parece problemática, na medida em que as identidades estão em constante transformação e as pessoas podem deixar de ser para tornar-se.

Em suma, acreditamos que as discussões propostas por Bucholtz e Hall (2005) conseguem condensar a noção de identidade com a qual estamos trabalhando. As autoras elencam cinco princípios ligados à construção de identidade:

(I) Princípio da emergência: aponta, como em diversos outros estudos, que a identidade é um fenômeno social e cultural, emergente de interações linguísticas. Corrobora, assim, com a perspectiva de que a identidade não é algo preexistente contida no sujeito, ela emerge, portanto, em alguma forma de discurso.

(II) Princípio da posicionalidade: desafia uma visão de grande circulação entre as ciências sociais que liga comportamento social a macro categorias identitárias, como idade, gênero e classe social. As autoras defendem o trabalho dos etnógrafos, pois afirmam que muitas vezes os indivíduos se orientam para categorias identitárias locais, numa perspectiva micro. Tais categorias seriam, além de locais, transitórias e temporárias.

(III) Princípio de indexicalidade: ocupa-se do mecanismo pelo qual a identidade é construída na interação. As autoras citam formas de indexação, entre elas: (a) menção explícita de categorias de identidade; (b) implicaturas e pressuposições em relação a posições identitárias do self e dos outros; (c) orientações avaliativas e epistêmicas durante a fala e papéis assumidos pelos falantes na interação; (d) o uso de estruturas linguísticas e sistemas que são ideologicamente associadas com pessoas e grupos específicos.

(IV) Princípio da relacionalidade: este quarto princípio afirma que as identidades não são autônomas ou independentes, elas, na verdade, mantêm uma relação com outras posições identitárias e outros atores sociais. Tais relações que se dão em complementaridade umas às outras são chamadas de técnicas de intersubjetividade. 
v. 10 (esp)

84-100

ago.

2020

(V) Princípio da parcialidade: o último princípio apresenta outras categorias e propõe que a construção da identidade pode ser em parte: (a) deliberada e intencional; (b) habitual e, por isso, menos consciente; (c) um resultado de uma negociação e contestação interacional; (d) um resultado da percepção e representação dos outros; e (e) um efeito de amplos processos ideológicos e estruturas materiais que podem se tornar relevantes para a interação.

Com isso, fica claro que o processo de construção identitária está em constante transformação, ele é fluido e adaptável. Esses princípios ora apresentados estarão presentes de forma mais diluída na seção dedicada à análise do corpus.

\section{Metodologia}

Esta pesquisa é de natureza qualitativa, o que não significa que questões quantitativas sejam totalmente ignoradas. Optamos por esse caminho por acreditarmos que é nesse tipo de pesquisa que os dados são interpretados, problematizados e colocados em discussão de acordo com perspectivas teóricas que embasam tais discussões.

Dessa forma, o corpus fonte de averiguação desta pesquisa é composto por dez relatos/entrevistas com moradores de Tejucupapo. As entrevistas, gravadas em áudio, foram feitas por Cordeiro da Silva (2015) para a realização de sua tese de doutorado, intitulada "Um estudo da construção complexa com cláusula completiva no português popular de Tejucupapo - PE". Essas entrevistas foram cedidas pelo pesquisador para a realização da dissertação da qual este trabalho constitui um recorte.

Os participantes são todos analfabetos e maiores de trinta e cinco anos de idade. Foram entrevistados seis mulheres e quatro homens, totalizando, assim, dez entrevistas. Os relatos foram sobre temas livres, o que fez com que eles se sentissem mais à vontade nos seus dizeres. Entre os temas estavam: as mudanças sofridas por Tejucupapo, educação, violência, família, trabalho etc. Pela variedade dos temas abordados, podemos perceber traços distintos de suas identidades. A gravação das entrevistas se deu na casa nos próprios entrevistados, depois de várias interações entre o pesquisador e os moradores. A duração de cada entrevista variou entre 1 h e 2h30, o que resultou em mais de 20 horas de gravação. 
Foram mapeadas todas as ocorrências do Processo Mental querer após criteriosa audição de cada entrevista. Em seguida, realizamos a transcrição das orações com o Processo Mental em apreço. Posteriormente, procedemos com a contagem das ocorrências do Processo querer no material transcrito, o que correspondeu a 149 casos. A etapa que se seguiu foi uma cuidadosa análise dessas inserções do Desiderativo querer, que teve por resultado o estabelecimento de três categorias, as quais poderão ser vistas na próxima seção.

\section{Análise dos dados}

Como mencionamos anteriormente, foram encontradas 149 ocorrências do Processo querer, Processo desiderativo de maior frequência no corpus, que se materializaram nos dados por meio de seis realizações gramaticais distintas, como pode ser visto na tabela abaixo.

\begin{tabular}{|c|c|}
\hline Formas do Processo querer & Número de ocorrências \\
\hline Quer & 57 \\
\hline Quero & 32 \\
\hline Queria & 32 \\
\hline Quiseram & 13 \\
\hline Querem & 10 \\
\hline Quis & 05 \\
\hline
\end{tabular}

Dois pontos se sobressaem nos relatos dos nossos falantes: as vontades de Deus e Jesus, além das expectativas de uma vida melhor em relação a trabalho, moradia, educação etc. O leitor vai verificar que a presença dos Experienciadores Deus e Jesus é tão significativa quantos os casos em que os Experienciadores são os tejucupapenses, quer sejam os moradores participantes da pesquisa ou outros moradores da comunidade

Assim, em relação à expressão dos desejos, a análise foi dividida em três partes: na primeira, vamos tratar da experienciação de vontades de entidades divinas, as quais são tomadas como preceitos para uma boa vida; na segunda, os anseios e desejos em relação às pessoas próximas aos tejucupapenses, sejam desejos dos próprios falantes em relação a essas pessoas, sejam desejos dessas pessoas trazidos pelos falantes; por fim, trataremos de desejos particulares dos próprios falantes, em 
v. 10 (esp)

84-100 ago. 2020 relação à sua vida, ao mundo e ao futuro. Percebamos que duas partes se destinam a desejos de outrem trazidos por eles, o que explica o número de construções com Experienciadores na terceira pessoa.

A experienciação de desejos divinos

De maneira geral, encontramos em nosso corpus muitas referências a Deus e a Jesus, de diversas formas, tanto na posição de Experienciador quanto de participante do Fenômeno da oração. A forma como eles invocam essas entidades para seus discursos mostra-nos não só a importância e o sentido que a religião tem na vida de alguns dos nossos tejucupapenses, mas também como tentam associar a religião a práticas e comportamentos do dia a dia. Vejamos abaixo os exemplos:

(05) O que mais ele (Deus) quer da gente... é que a gente faça o bem... faça o bem sem olhar a quem... e também ele quer que a gente faça o bem a quem não faz o mal...

(06) A gente só deixa de pecar quando morrer... mas viveu aqui... a gente não tá livre de nada... então Deus quer que a gente deixe mais de fazer tanta coisa ruim... pra que ele aja melhor na nossa vida...

(07) e é isso que Deus quer... se hoje você é uma pessoa boa... amanhã Deus quer que você seja melhor do que hoje... pra você ser uma pessoa boa... não precisa ser crente não... se for uma pessoa boa... que goste de ajudar...

Podemos perceber que as vontades de Deus são apresentadas como uma espécie de conselho. Todos são configurados com o desdobramento atual com o tempo no presente simples. Além disso, enquadram-se no tipo desiderativo "esperar", no qual as orações com o desejo são projetadas e iniciadas com o "que" do subjuntivo. Os exemplos de (05) a (07) apresentam certas vontades divinas que, se fossem seguidas, poderiam ser a solução para determinados problemas ou situações da vida humana. Os falantes se colocam como um propagador das vontades experienciadas por Deus. Percebemos, então, a religiosidade como um forte traço da identidade dos tejucupapenses.

Nos exemplos supracitados, é possível dizer que há uma tentativa de "injunção ideológica" por meio da religião. É um aconselhamento que parte do falante, o qual ele toma para si como 
discurso, mas que subjaz de uma orientação ideológico-religiosa maior que ele. Trazem tais entidades religiosas como suporte e solucionador de empecilhos. Todos os exemplos apresentados mostram o Processo querer na terceira pessoa e projetam o desejo numa oração encaixada que instancia o participante fenômeno.

Novos anseios tejucupapenses

Se no tópico anterior, os tejucupapenses compreendem que as vontades religiosas devem influenciar o comportamento das pessoas, na discussão feita neste tópico, os exemplos demonstram que eles vão argumentar a respeito de como o tempo mudou as vontades e as expectativas das pessoas próximas, como seus filhos e pessoas da comunidade. Ou seja, nos primeiros casos, há um comportamento que é determinado por intermédio de uma conduta baseada na ordem divina, já no segundo, as determinações ocorrem devido a questões temporais e a mudanças da sociedade. Se lá, era um comportamento de caráter ético e moral, aqui é de caráter social.

Nos exemplos a seguir, nossos falantes revelam desejos de outrem para com as coisas do mundo. Os tejucupapenses entendem que as mudanças comportamentais pelas quais passaram as pessoas e que resultaram em novas vontades têm como grande aliado o passar do tempo. As pessoas expressam novos desejos no decorrer da evolução temporal.

(08) agora o pessoal tão fazendo tudo assim (de tijolo)... ninguém quer mais casa de taipa... não quer mais nada... mas essa casa era de taipa... eu trabalhei e levei anos e anos pra fazer ela...

(09) aquelas esteiras... antigamente é onde a gente dormia... hoje em dia ninguém quer dormir numa cama mais velha... antiga... hoje em dia só quer a cama box... é muito do luxo... viu

(10) Tem muita gente agora tudo trabalhando... hoje em dia tem tudo... não trabalha quem é preguiçoso... muitos não querem varrer rua... se envergonha pra varrer rua...

(11) DOC: Vocês faziam como com água antigamente...

INF: água da cacimba... abria um buraco até aparecer água no olho d'água.. aí... enchia e o pessoal botava 
v. 10 (esp)

84-100

ago.

2020 água... mas agora ninguém quer mais botar água de cacimba... nem água de bica... só querem agora água de torneira...

Os exemplos apresentados acima se associam com diversos outros trechos ora encontrados nas entrevistas, pois têm no seu bojo uma motivação temporal. Por meio de termos e expressões que localizam temporalmente o dizer, como "hoje em dia", "antigamente", "hoje" e "mais", podemos perceber que as passagens mencionadas por nossos falantes se configuram de forma comparativa com tempos anteriores. Dessa forma, podemos entender que aquilo que atualmente acontece, ou seja, o que é desejado e almejado hoje, não o era num tempo anterior. Essas expressões temporais apontam para o caráter transitório e local da identidade, mencionados por Bucholtz e Hall (2005). Essas novas identidades surgem e individualizam os tejucupapenses, na medida em que se apresentam como desejos particulares deles, ou seja, desejos locais.

Em todos os excertos, é possível notar, por meio das falas dos entrevistados, que seus conterrâneos já não aceitam um estado ainda mais precário de vida ao qual se sujeitavam em outros tempos. Com o passar dos anos, as necessidades foram mudando e seus desejos se alinhando com pessoas de fora de Tejucupapo, ainda que a situação de vida não fosse das melhores. Houve mudanças em relação à estrutura das casas (08), não mais de taipa; também não são mais desejadas casas muito afastadas, no mato, por exemplo; e já não se aceita dormir em qualquer lugar (09), como antes. Outro quesito, no qual houve mudanças as quais também foram atribuídas ao tempo, diz respeito ao trabalho e às suas condições (10). Diferentes dos desejos divinos, estes novos anseios não dizem respeito a desejos abstratos, mas a vontades pontuais e específicas, ligadas a condições de vida.

\section{Vontades pessoais}

Por fim, trazemos desejos e vontades apresentados pelos falantes em relação a eles mesmos. Suas expectativas e anseios sobre os mais diversos temas, sem qualquer menção aos desejos de outrem. Nessa seção, além do Processo querer, utilizamos também um exemplo com o Processo esperar no sentido de ansiar, de ter expectativa em relação a algo. Utilizamos o esperar por acreditarmos que o referido Processo sintetiza toda a discussão realizada nesta seção. 
(12) eu trabalhava direto... eu pensando que ele ia classificar minha carteira... só que ele tava com safadeza comigo... de domingo a domingo... ele "venha trabalhar"... e eu ia... eu não vou pisar na bola... porque eu queria crescer na empresa... passar de trabalhador rural pra tratorista...

(13) A gente fica imaginando da pessoa caindo a idade... agora eu só não quero morrer... né... a gente morre a pulso... porque chegou o dia da gente ir... Deus marcou o tempo... a época... aí a gente tem que ir... mas dizer que a velhice é bom... num é não... a gente quer fazer as coisas e não pode...

(14) eu não tenho esse negócio comigo não... você pode trazer seu pai... sua mãe... sua namorada... o seu vizinho... o seu amigo... seja quem for... você chegando aqui... graças a Deus eu to de bem com a vida...E quero ver todo mundo feliz da vida... só não quero que ninguém chegue aqui pra me complicar...

(15) A vida é cheia de altos e baixos mas a gente espera pelo melhor... porque quem tem Jesus tem tudo... como eu já falei... e a cada dia as coisas tá indo... tá melhorando... é sobre estudo, curso...

Neste último bloco de exemplos, apresentamos ao leitor aspectos pelos quais é possível visualizar traços de identidades de nossos tejucupapenses que não tinham sido destacados em outras seções. Isso ocorreu porque, através de desejos e vontades individuais, eles deixaram transparecer anseios que não costumam ser ditos em conversas quaisquer. Encontramos ocorrências do Processo querer ligados às mais variadas áreas e assuntos. Vale destacar que a maioria dos exemplos desse bloco são do tipo "querer" mais oração projetada finita (fenômeno) e o Experienciador é o participante que vivencia o desejo.

No trecho (12), o falante expressa sua vontade de evoluir na empresa onde trabalhava, se de um lado, temos o desejo de galgar melhores posições no trabalho, de outro temos a vontade de viver. A falante, no exemplo (13), sentindo o peso da idade, expressa o desejo de não querer morrer e a vontade de querer poder fazer determinadas atividades, mas já não conseguir mais. Na segunda inserção do Processo querer desse exemplo, a falante generaliza seu querer e o coloca como vontade de todas as pessoas que estão na categoria temporal velhice. 
v. 10 (esp)

84-100 ago. 2020
Os dois últimos exemplos apresentam, de certa forma, uma síntese de quem são essas pessoas. No caso (14), o falante diz querer ver felizes todos que chegam a sua casa, não importa quem seja e ressalta que não quer ter problemas com ninguém. Podemos ampliar esse desejo de felicidade para todas as outras pessoas que não provoquem qualquer tipo de confusão. Em geral, os tejucupapenses querem que cada pessoa viva bem, do jeito que lhe convier. Já em (15), exemplo no qual abrimos exceção e analisamos o uso do Processo esperar, é possível inferir o sentimento de esperança por um futuro melhor expressado pela falante, que o associa ao fato de ter Jesus em sua vida. Tal anseio é realizado pela única utilização do Processo esperar nessa acepção encontrada no corpus. Lançamos mão de tal Processo aqui pois, de certa forma, ele resume a crença que os tejucupapenses têm em um amanhã mais próspero, demonstrada a partir do referido exemplo.

\section{Considerações finais}

Nesta pesquisa, por intermédio do Processo Mental Desiderativo querer, extraímos dos discursos dos moradores, seus anseios e suas vontades em relação aos mais variados assuntos e às mais variadas pessoas. Para organizar a explicitação desses desejos, foi feita uma categorização de acordo com o Processo querer e seus Experienciadores.

Dessa forma, pela análise empreendida, é possível formular três hipóteses para expressar o querer veiculado pelo discurso dos moradores entrevistados: (a) Deus como Experienciador do desejo, vimos que, por meio da religião, eles sugerem ações e dão conselhos para o que consideram um bom modo de viver; (b) vontades ligadas às pessoas próximas a eles, em relação a trabalho, qualidade e modo de vida etc.; (c) os anseios dos tejucupapenses entrevistados para com suas próprias vidas; aqui é possível inferir um sentimento de esperança, de melhorias. Eles desejam uma oportunidade para mudar de vida. Os relatos instanciam esse tom: o desejo de que o lugar, as pessoas e suas vidas possam melhorar, o desejo de que eles possam viver de forma mais digna.

Assim, ao delinear um perfil dos moradores de Tejucupapo, podemos evidenciar a religiosidade como traço constitutivo dos moradores entrevistados, funcionando como um guia para um bom 
comportamento. Vimos, também, como os entrevistados percebem mudanças na identidade dos seus conterrâneos. Um novo perfil de tejucupapense é percebido por meio de novos desejos em relação aos mais variados temas. Ao ressaltar esses novos anseios, os tejucupapenses de nossa pesquisa marcam uma diferença entre eles e os moradores mais jovens da região, a identidade aqui é marcada pela diferença. De forma geral, nossos falantes se mostram otimistas e esperançosos com o futuro, exprimindo positividade em suas falas.

O que captamos neste trabalho é um extrato da identidade de uma pequena parte da população, dessa forma, se mudássemos as pessoas, os resultados poderiam, e certamente seriam, um tanto diferentes. Se, com essas mesmas pessoas, as entrevistas forem realizadas daqui a cinco ou dez anos, é provável que outros traços estivessem presentes numa futura análise. Justamente por isso, este trabalho mostra que não se esgotam as possibilidades de análise da identidade seja dos tejucupapenses seja de outro grupo de pessoas.

\section{Referências}

BUCHOLTZ, Mary; HALL, Kira. Identity and Interaction: A Sociocultural Linguistic Approach. Discourse Studies, v. 7, n. 4-5, p. 585-614, 2005.

CORDEIRO DA SILVA, Emanuel. Um estudo da construção complexa com cláusula completiva no português popular de Tejucupapo - PE. 2015. Tese (Doutorado em Linguística) - Programa de Pós-graduação em Letras, Universidade Federal de Pernambuco, Recife, 2015.

FAIRCLOUGH, Norman. Discurso e Mudança Social. Brasília: Editora UnB, 2001.

FIGUEREDO, Giacomo Patrocinio. Introdução ao perfil metafuncional do português brasileiro: contribuições para os estudos multilíngues. Tese (Doutorado em Linguística Aplicada) - Programa de Pós-Graduação em Estudos Linguísticos, Faculdade de Letras da UFMG, Belo Horizonte, 2011.

FURTADO DA CUNHA, Maria Angelica; SOUZA, Maria Medianeira de. Transitividade e seus contextos de uso. São Paulo: Cortez, 2011.

FUZER, Cristiane; CABRAL, Sara Regina Scotta. Introdução à gramática sistêmico-funcional em língua portuguesa. Santa Maria: UFSM, 2010.

GHIO, Elsa; FERNÁNDEZ, María Delia. Lingüística Sistémico Funcional: Apicaciones a La lengua española. 1. ed. Santa Fe: Universidad Nacional Del Litoral, Waldhuter, 2008.

HALLIDAY, Michael Alexander Kirkwood.; MATTHIESSEN, Christian Mathias Ingemar Martin. Introduction to Functional Grammar. 4. ed. London: Arnold, 2014 . 
v. 10 (esp)

84-100 ago. 2020

MAGALHÃES, Celia Elisa Alves de. Então me bateu um grande frio na barriga. Em cena, o professor coordenador de inglês: um estudo sobre identidade e avaliação. 2013. Dissertação (Mestrado em Letras/Estudos da Linguagem) Programa de Pós-Graduação em Estudos da Linguagem, Pontifícia Universidade Católica do Rio de Janeiro, 2013.

MARCUSCHI, Luiz Antônio. Produção textual, análise de gêneros e compreensão. São Paulo: Parábola Editorial, 2008.

MOITA LOPES, Luiz Paula da; BASTOS, Liliane Cabral. Identidades: recortes multi e interdisciplinares. Campinas, SP: Mercado de Letras, 2002.

SILVA, Tomaz Tadeu da; HALL, Stuart; WOODWARD, Kathryn. Identidade e diferença: a perspectiva dos estudos culturais. Petrópolis: Vozes, 2000.133 p. 